\section{Betting on betatrophin}

\section{By Lev Osherovich, Senior Writer}

Researchers at Harvard University have discovered a hormone that promotes pancreatic islet $\beta$ cell proliferation in mice. ${ }^{1}$ Evotec AG and Johnson \& Johnson's Janssen Pharmaceuticals Inc. unit have rights to the molecule and plan to turn it into a preclinical type 2 diabetes candidate this year. However, the hormone's relevance to disease in humans needs to be fleshed out.

$\beta$ Cells are the source of insulin, the hormone that controls blood sugar. $\beta$ Cells die off in both type 1 and type 2 diabetes, albeit for different reasons-autoimmune destruction in the former, exhaustion in the latter.

Therapies for both forms of diabetes have largely focused on raising insulin production by what few $\beta$ cells remain, but this approach brings diminishing returns in advanced cases of disease. The ideal approach would be to correct the metabolic or autoimmune problems that trigger the illness and then restore the full complement of $\beta$ cells through regenerative therapy.

Now, a team led by Douglas Melton, professor of stem cell and regenerative biology at Harvard and co-director of the Harvard Stem Cell Institute, has identified the most potent means yet to stimulate $\beta$ cell expansion-the liver-derived peptide hormone betatrophin.

"Betatrophin is a molecule that stimulates $\beta$ cell proliferation, which is one attractive mechanism to expand $\beta$ cell function," said Evotec CSO Cord Dohrmann.

Previous studies by other teams have identified pathways and mechanisms that can modestly stimulate new $\beta$ cell growth. These include peptide hormones such as glucagon-like peptide-1 (GLP-1) ${ }^{2}$ and small molecule agonists of adenosine $\mathrm{A}_{2 \mathrm{~A}}$ receptor $\left(\mathrm{ADOR}_{2 \mathrm{~A}}\right)$, as well as transdifferentiation approaches that convert other cell types into $\beta$ cells. ${ }^{3}$

"When it comes to making new $\beta$ cells, what sets this new work apart from prior work is the extent to which it stimulates cell proliferation," said Dohrmann. "You can see two- to fivefold stimulation of proliferation with other pathways, but this causes a 10-20-fold increase in $\beta$ cell numbers."

"While there are other strategies for causing $\beta$ cell replication, none of them are as potent and specific," added Melton.

\section{Artificial resistance}

Prior studies by other researchers hinted that $\beta$ cell mass and insulin levels could rise during insulin resistance, an early sign of type 2 diabetes. ${ }^{4}$ To uncover why, Melton's team set up a mouse model in which insulin signaling was blocked with a pharmacological antagonist, leading to an artificial state of insulin resistance. The team then analyzed gene expression in a variety of tissues.

The group found that blocking insulin signaling led to the upregulation of betatrophin, a previously unknown 198-amino-acid secreted protein. The upregulation occurred in liver and fat tissues but not in the pancreas. Two other models for type 2 diabetes also showed higher betatrophin expression in the liver and fat than healthy controls.

The team reasoned that betatrophin relayed a signal from the liver and fat to the pancreas to compensate for insulin insensitivity. Indeed, transgenic overexpression of betatrophin in the liver led to a 17 -fold increase in the rate of $\beta$ cell replication in the pancreas compared with that seen in vector-treated controls.

Eight days after treatment, mice receiving extra betatrophin had three times as much $\beta$ cell mass and produced about two times as much insulin. Those animals had lower fasting glucose levels and greater insulin sensitivity than vector-treated controls.

Results were published in Cell.

\section{Insulin insult}

The Cell findings help explain how the body adapts to dysregulation of insulin signaling, but questions remain about betatrophin's mechanism of action.

"Increased $\beta$ cell mass in response to insulin resistance is a welldocumented phenomenon," said Hui Tian, VP of research at NGM Biopharmaceuticals Inc. "However, the factors or pathways that mediate this process are still unclear."

Like Melton's team, NGM is trying to identify factors that raise $\beta$ cell levels to treat metabolic disease. The company did not disclose whether it has identified betatrophin in its in vivo screens for $\beta$ cell-boosting factors nor the identity of lead candidates in its $\beta$ cell-regeneration collaborations with Daiichi Sankyo Co. Ltd. and JDRF, a not-for-profit group.

Olov Andersson, assistant professor in the Department of Cell and Molecular Biology at the Karolinska Institute, wanted to know whether betatrophin acted directly on $\beta$ cells or on some other tissue.

"We have to determine whether it directly affects $\beta$ cells," said Andersson. "An alternative might be that there's a relay from another organ. To test this, you could isolate islets and treat them in vitro."

Last year, Andersson and collaborators at the University of California, San Francisco reported that agonists of ADORA $_{2 \mathrm{~A}}$ could promote $\beta$ cell proliferation in zebrafish and mice. ${ }^{5}$

Another goal is to identify betatrophin's receptor, which may or may not be a known player in $\beta$ cell proliferation.

"Betatrophin stands out from other $\beta$ cell mitogens by being so potent," said Andersson. "We don't know the downstream mediators, but these might be factors such as GLP-1," which is another peptide hormone that promotes $\beta$ cell proliferation. 


\section{Beta strike}

As potent as betatrophin is in mice, the bigger question is whether the hormone will have an effect in diabetic humans.

"Even though we do know that betatrophin exists in humans, its relevance to human disease still needs to be demonstrated," said Dohrmann.

Andrew Stewart noted that many compounds and targets for $\beta$ cell proliferation have failed in the translational leap from mouse to man.

"There are now nearly a hundred different molecules that drive rodent cell replication that fail to do so in human $\beta$ cells," said Stewart. "The elephant in the room is: what about human $\beta$ cells?" Stewart is professor of medicine, endocrinology, diabetes and bone disease and director of the Diabetes, Obesity and Metabolism Institute at the Icahn School of Medicine at Mount Sinai.

Stewart said one reason for the lack of success of prior strategies to boost human $\beta$ cell replication is that mouse models typically involve young animals with robust capacity for pancreatic regeneration.

In contrast, typical patients with type 2 diabetes are middle-aged with heavily damaged pancreases that have exhausted the ability to naturally regenerate.

Stewart said several previous studies "have shown that as rodent $\beta$ cells age, they become refractory to replication by things that work in juvenile rodents."

Thus, it would be useful to test whether exogenous betatrophin can regenerate $\beta$ cells in older rodents. Another key experiment would be to test the effect of purified recombinant betatrophin on cultured pancreatic islets obtained from diabetic cadavers.

Dohrmann and Melton said experiments along these lines are under way. Evotec and Melton's team also are testing the effect of betatrophin on insulin response in a range of type 2 diabetes models.

Although the most obvious application of betatrophin is in type 2 diabetes, Melton thinks there is an opportunity to use the hormone to treat type 1 diabetes in conjunction with immunomodulatory therapy. He said between a patient's initial diagnosis and the complete destruction of $\beta$ cells, there is a window of opportunity to halt autoimmunity and regenerate the remaining $\beta$ cells.

"My idea is that when you have a new-onset type 1 diabetes patient, there's still a lot of $\beta$ cells," said Melton. "A simple experiment is to combine betatrophin with an immunosuppressant."

Another possibility is to administer betatrophin prophylactically in siblings of children with type 1 diabetes, who have a high risk of developing the disease.

Dohrmann said that betatrophin could be combined with DiaPep277, an immunomodulatory compound that Evotec has in Phase III testing for type 1 diabetes in partnership with Clal Biotechnology Industries Ltd. and Teva Pharmaceutical Industries Ltd.

The findings described in the Cell paper are patented by Harvard. The IP is licensed to Evotec and Janssen under a 2011 deal. ${ }^{6}$ Dohrmann said betatrophin is the principal component of that deal, the details of which were not disclosed until now. Janssen will manufacture and test recombinant betatrophin in preclinical models, whereas Evotec will conduct in vivo and in vitro pharmacology studies to identify betatrophin's receptor and mechanism of action.

Osherovich, L. SciBX 6(17); doi:10.1038/scibx.2013.405

Published online May 2, 2013

\section{REFERENCES}

1. Yi, P. et al. Cell; published online April 25, 2013; doi:10.1016/j.cell.2013.04.008

Contact: Douglas A. Melton, Harvard University, Cambridge, Mass. e-mail: dmelton@harvard.edu

2. Suen, C.S. \& Burn, P. Drug Discov. Today 17, 89-95 (2012)

3. Noguchi, H. Curr. Diabetes Rev. 6, 184-190 (2010)

4. El Ouaamari, A. et al. Cell Rep. 3, 401-410 (2013)

5. Andersson, O. et al. Cell Metab. 15, 885-894 (2012)

6. Lou, K.-J. SciBX 6(4); doi:10.1038/scibx.2013.80

\section{COMPANIES AND INSTITUTIONS MENTIONED}

Clal Biotechnology Industries Ltd. (Tel Aviv:CBI), Tel Aviv, Israel Daiichi Sankyo Co. Ltd. (Tokyo:4568; Osaka:4568), Tokyo, Japan Evotec AG (Xetra:EVT), Hamburg, Germany

Harvard Stem Cell Institute, Cambridge, Mass.

Harvard University, Cambridge, Mass.

Icahn School of Medicine at Mount Sinai, New York, N.Y. Johnson \& Johnson (NYSE:JNJ), New Brunswick, N.J.

JDRF, New York, N.Y.

Karolinska Institute, Stockholm, Sweden

NGM Biopharmaceuticals Inc., South San Francisco, Calif. Teva Pharmaceutical Industries Ltd. (NYSE:TEVA), Petah Tikva, Israel

University of California, San Francisco, Calif. 